\title{
Bolivia-Chile: el reciente fallo de la Corte Internacional de Justicia
}

\author{
Luis Winter Igualt
}

\section{i. Observaciones Preliminares}

Rosalyn Higgins, la ex Presidenta de la Corte Internacional de Justicia, se refirió - en una publicación de $2009^{1}$ - a las percepciones alternativas del Derecho Internacional. Está la percepción clásica del Derecho Internacional como un conjunto de reglas, imparcialmente aplicadas y cuya fuerza reposa en el conocimiento público de ellas, reglas que serán aplicadas en todas las ocasiones.

Sir Gerald Fitzmaurice sostiene que la Corte Internacional es una Corte de Derecho. Puede tomar en cuenta principios morales solamente en la medida en que estos principios tengan expresión suficiente en términos legales. Según Fitzmaurice, el derecho existe para servir una necesidad social, pero precisamente por esta razón puede hacerlo solamente a través y dentro de las necesidades de su propia disciplina. Si no fuese así, no se estaría prestando un servicio legal.

Pero no todos siguen la visión clásica, agrega Higgins. Quienes miran el

1 Themes and Theories, Rosalyn Higgins. Oxford University Press 2009. Published 2009 by Oxford University Press. derecho desde la ciencia política, tienen un enfoque profundamente diferente. Rechazan la noción del derecho como "reglas", debido a que estas son tendencias acumuladas de decisiones pasadas, que no identifican las variables que condujeron a esas decisiones, no las relacionan con las cambiantes condiciones de los problemas de hoy, ni indican preferencias para el futuro. Las decisiones pasadas son un componente esencial del proceso de toma de decisiones contemporáneo, pero ellas no son suficientes. Rechazan la noción del derecho como reglas y favorecen el derecho como proceso - una forma particular del proceso de toma de decisiones-que no pretende ser neutral o sin valor, sino tener autoridad.

Estas visiones alternativas y ciertos fallos de la Corte Internacional de Justicia, cuyo componente político ha sido también relevado por juristas $\mathrm{y}$ académicos ${ }^{2}$, hicieron surgir inquietudes en ciertos sectores de la opinión

2 Legitimacy and International Courts. Edited by Nienke Grossman, Harlan Grant Cohen, Andreas Follesdal y Geir Ulfstein. Studies on International Courts and Tribunals. Cambridge University Press. 2018 
pública chilena. Más aún cuando la Cancillería de Bolivia, en el marco del programa de televisión "Diplomacia de los pueblos por la vida," dio a conocer en febrero de 20I8, a través de su cuenta oficial en YouTube, una entrevista a los abogados que defendían su causa en La Haya. Allí, y con anterioridad a los alegatos orales, los juristas señalaron que "el derecho no siempre está en pos de la justicia. Hay otros fines que persigue, como la seguridad jurídica, que a veces es una bomba de relojería sobre la justicia”.

Los alegatos orales realizados durante la segunda quincena de marzo de este año no dejaron dudas acerca de la estrategia seguida por Bolivia durante el proceso. Había tratado de buscar un fallo que, alejándose de la estricta aplicación del derecho, diera crédito a un planteamiento centrado en sentimentalismos, en figuras jurídicas que nunca crearon obligaciones, y en un relato histórico que, como señaló a la Corte el abogado de Chile, Daniel Bethlehem: "Chile no acepta la versión histórica que presenta Bolivia, tampoco la manera como la proyecta hasta hoy. Es una versión parcial, tendenciosa e indignante" ${ }^{\text {" }}$.

Como veremos a continuación, estas dudas se disiparon completamente el I $^{\circ}$ de octubre pasado, al dictar la Corte un fallo estrictamente apegado al Derecho Internacional y que dio íntegramente la razón a los argumentos jurídicos planteados por Chile en su defensa.

\section{Objeto de la Controversia}

Si bien, conforme a lo pedido por Bolivia, el objeto de la controversia era la obligación de Chile de negociar, de buena fe y de manera efectiva, con Bolivia un acceso plenamente soberano al Océano Pacífico ${ }^{4}$, indudablemente lo buscado por Bolivia era - aunque en forma indirecta- la revisión o anulación del Tratado de 1904. De allí que Chile opusiera la excepción de incompetencia de la Corte, basada en el numeral VI del Tratado de Soluciones Pacíficas (Pacto de Bogotá), disposi-

3 CJI. Verbatim Record. Pág.60 par. 4

4 Memoria de Bolivia. Vol. 2. Pág. I00. Par. 500. ción que excluye de la competencia del Tribunal los asuntos ya resueltos por arreglo de las partes, o por laudo arbitral, o por sentencia de un tribunal internacional, o que se hallen regidos por acuerdos o tratados en vigencia en la fecha de la celebración del presente Pacto. En su fallo del 24 de septiembre de 20I5, la Corte rechazó por I4 votos a 2 la excepción preliminar por estimar que, incluso, si se pudiera suponer que el objeto último perseguido por Bolivia fuese el acceso soberano al Océano Pacífico, esto no había sido solicitado por el demandante, sino que declarara que Chile estaba obligado a 
negociar y, si fuese así, si Chile había faltado a ese compromiso ${ }^{5}$. Quedó, de este modo, fijado el objeto de la controversia "en la cuestión de saber si Chile tenía la obligación de negociar de buena fe un acceso soberano a Bolivia al Océano Pacífico y, de ser efectivo, si Chile había faltado a esa obligación. Pero junto con decidirlo así, adelantó que, en un fallo sobre el fondo y en el evento en que este determinara que
Chile estaba obligado a negociar, no le correspondería a la Corte pronunciarse sobre el resultado de tal negociación. De esta manera, el objeto quedó reducido a una obligación de medios y no de resultado. Fue la razón por la que nuestro país señaló, desde el comienzo, que en la sentencia final no estaba comprometida parte alguna de nuestra soberanía.

\section{EL ORIGEN, FUENTE O FUNDAMENTO DE LA OBLIGACIÓN JURÍDICA DE NEGOCIAR}

Desde un comienzo se observó en Bolivia falta de claridad e incluso posiciones contrapuestas respecto de un tema esencial, el verdadero origen de la obligación de negociar. En su memoria, Bolivia señaló tener derecho a un acceso soberano al mar, variando de posición en sus alegatos sobre la excepción preliminar. De haber sostenido en esos alegatos que tenía derecho a un acceso soberano al mar, la Corte debería haber aceptado la excepción chilena, por cuanto ello implicaba directamente alterar el Tratado de 1904. Por otra parte, cabe hacer presente que, al carecer Bolivia de un derecho, tampoco le era posible afirmar que Chile estaba obligado a concederlo. Las obligaciones deben tener una fuente, de otro modo no existen. La búsqueda de esta fuente jurídica, basada en la historia de las relaciones chileno-bolivianas,

5 ICJ. Fallo de 24 de Septiembre de 2015. ocupó gran parte del juicio. Bolivia acudió a hechos, acuerdos, conductas y declaraciones unilaterales que, a su juicio, daban nacimiento a esa obligación de negociar. Y deliberadamente no fue clara al argumentar en cuál de esos episodios daba nacimiento a la obligación. Ello motivó, durante los alegatos orales, al Juez británico, Christopher Greenwood, a preguntar a los abogados bolivianos: ¿en qué fecha sostiene Bolivia que se concluyó un acuerdo para negociar? La respuesta fue igualmente confusa, pues el abogado de Bolivia, Payam Akhavan, respondió en los mismos términos en que había planteado la situación su representada en la Memoria ${ }^{6}:$ "No hay un principio en Derecho Internacional que exija un solo momento mágico cuando los acuerdos o compromisos aparecen

$6 \quad$ ICJ. Verbatim 8 de Mayo de 20I5. Pág. 33 $\mathrm{N}^{\circ}$. 
de la nada, como en la historia de la creación. En consecuencia, la tesis de Bolivia es que hay varias instancias de acuerdos con Chile y cada una de ellas constituye un compromiso legal obligatorio".

En otras oportunidades, sus abogados plantearon que el origen de la obligación se encontraba en cada uno y en todos los momentos y ocasiones citadas. Pero a los Acuerdos y Declaraciones Unilaterales, Bolivia fue agregando nuevas supuestas fuentes, la Aquiescencia, las Legítimas Expectativas, las Resoluciones de la oeA, el artículo $2 \mathrm{~N}^{\circ} 3$ de la Carta de la onu y, finalmente, el efecto acumulativo de todas ellas. En otras palabras, agotó el stock de fuentes posibles que pudieran originar la obligación jurídica de negociar pedida por Bolivia.

La búsqueda de ese eslabón faltante, como lo llamó el abogado de Chile, Jean Marc Thouvenin, se transformó en un dolor de cabeza permanente para Bolivia ${ }^{7}$, toda vez que no es posible afirmar la existencia de una obligación jurídica sin un hecho o Acto Jurídico realizado con la intención de producirlo.

\section{LOS ANTECEDENTES HISTÓRICOS Y DE HECHO DEL CASO}

El contexto histórico es el cimiento de la construcción del caso boliviano. Impedido, por razones jurídicas, de plantear la revisión del Tratado de 1904, Bolivia recurrió a la historia de nuestras relaciones, viendo en diversas ocasiones y períodos, el nacimiento y permanencia de una obligación de negociar por parte de Chile para concederle un acceso soberano al Océano Pacífico. Para ello, la Corte examinó, en orden cronológico eventos que han marcado la relación entre Bolivia y Chile. Pasó revista a hechos anteriores a 1904, incluyendo el Tratado de Transferencia de Territorio de I895 que, declaró, jamás entró en vigor. Aludió

\footnotetext{
7 ICJ. Verbatim 22 de marzo de 20I8. Pág. 57 $\mathrm{N}^{\circ} 77$.
}

al Tratado de Paz de 1904, haciendo hincapié en su artículo II que reconoce que el territorio ocupado por Chile en aplicación del Pacto de Tregua de I884 fue delimitado entre Bolivia y Chile y es de dominio absoluto y perpetuo de Chile. Se refirió a los intercambios y declaraciones de los años 20, deteniéndose en el Acta suscrita ese año, a intercambios posteriores, a la propuesta Kellog de 1926 y al Memorándum Matte del mismo año. Más adelante citó la reacción boliviana al Tratado de 1929 con Perú, el intercambio de notas de 1950, y el Memorándum Trucco de 196I. Finalmente, analizó el proceso de Charaña, las Declaraciones y Resoluciones ante la OEA, el enfoque fresco de 1986-I987, la Declaración de Algarve y 
la Agenda de los 13 puntos. De todos ellos, Bolivia se fijó particularmente en los Acuerdos Bilaterales y en las Declaraciones y otros Actos Unilaterales de Chile, hechos que, conforme a su criterio, daban origen a la obligación de negociar.

\section{Consideraciones PREliminares del Fallo}

Tras exponer los antecedentes históricos y de hecho del juicio, y antes de analizar los fundamentos jurídicos de Bolivia, la Corte hizo tres consideraciones generales. Explicó, en primer lugar, las características que debe reunir una obligación de negociar. Dijo que, si bien los Estados son libres para entrar en negociaciones o ponerles fin, si lo hacen, ellas deben ser significativas, es decir, conducirse haciendo el máximo de esfuerzos para llegar a un acuerdo, aunque este no se logre. El acuerdo no es obligatorio. En seguida, muy importante es el recuerdo que hizo del objeto de la controversia, el que, como se señaló anteriormente, fue fijado en la excepción preliminar, acotando el resultado del juicio solamente a si había o no obligación de negociar. Finalmente, dejó en claro que Bolivia entendía el término "acceso soberano" como aquel en que un Estado no depende de nada ni de nadie para gozar de dicho acceso. Acceso soberano es un régimen que asegura una vía ininterrumpida de Bolivia al Océano Pacífico.

\section{FundAMENTOS JURÍDICOS DE LA OBLIGACIÓN DE NEGOCIAR Y POSICIÓN DE LA CORTE}

La Corte inició el análisis de los fundamentos jurídicos planteados por Bolivia, fijando su propia posición respecto de la obligación de negociar. "En el Derecho Internacional, afirmó, la existencia de una obligación de negociar tiene que ser establecida de la misma manera que cualquier otra obligación jurídica. La negociación es parte de la práctica común de los Estados en sus relaciones bilaterales y multilaterales" Agregó que, para que exista una obligación de negociar basada en un acuerdo, los términos empleados por las Partes, el objeto y las condiciones de las negociaciones, deben demostrar una intención de obligarse jurídicamente. Esta intención, señaló, en la ausencia de términos expresos que indiquen la ausencia de un compromiso jurídico,

$8 \quad$ Fallo de i de octubre de 20I8. Pár. 9I 
puede ser establecida sobre la base de un examen objetivo de toda evidencia.

Bajo estos parámetros, es decir, la importancia de la negociación en las relaciones internacionales y la necesidad de una presencia clara del elemento intencionalidad para obligarse jurídicamente, la Corte pasó a analizar cada uno de los ocho supuestos fundamentos jurídicos (así los denomina) en que Bolivia basa su demanda contra Chile: Acuerdos bilaterales; Declaraciones y otros Actos Unilaterales, Aquiescencia, Estoppel, Legítimas Expectativas, Art. $2 \mathrm{~N}^{\circ} 3$ de la Carta de las Naciones Unidas, Resoluciones de la oea y Efecto Acumulativo de dichos fundamentos.

Como se señala más arriba, la parte más extensa del fallo es aquella en que analiza si los hechos planteados en el juicio, constituyen Acuerdos Bilaterales y Actos Jurídicos Unilaterales, derivándose de dichas fuentes la obligación jurídica de negociar esgrimida por Bolivia.

En cuanto a los Acuerdos Bilaterales, el Fallo recurre a la Convención de Viena de Derecho de los Tratados, reconociendo que, conforme al Derecho Internacional Consuetudinario reflejado en su art. 3, "los Acuerdos no celebrados por escrito" pueden tener valor jurídico pero que, en este caso, dichos acuerdos requieren de la intención de las Partes para vincularse jurídicamente, lo que también es válido para los acuerdos tácitos. Recuerda, asimismo, que la prueba de un acuerdo jurídico tácito debe ser convincente. Bajo este elevado prisma, el Fallo analiza los intercambios diplomáticos de la década de 1920 , el intercambio de notas de 1950, la Declaración de Charaña de 1975 , los comunicados de 1986 , la Declaración de Algarve y la Agenda de los I3 puntos.

Respecto del Acta de 1920 e intercambios posteriores, la Corte señaló ver en ella un texto que no contiene compromisos y no es vinculante por expresa disposición del propio Canciller boliviano y aceptación tácita de su contraparte chilena. Además, descartada el Acta de 1920, también descartó los intercambios posteriores, aunque expresa que el Memorándum dirigido por el Canciller chileno Jorge Matte, en 1926, al Secretario de Estado norteamericano, Frank Kellog 9 , sí podría haber indicado una obligación de negociar si hubiese estado dirigida a Bolivia.

Siempre citando la Convención de Viena, se refiere al intercambio de notas de 1950 , diciendo que este hecho puede originar un Tratado, pero siempre que en su canje se especifique dicho efecto, lo que no sucedió en este caso. Asimismo destacó que en la práctica internacional, el intercambio de notas se hace con un mismo lenguaje, lo que tampoco se advierte aquí. Por último, señaló que de las palabras utilizadas por Chile: "estar dispuesto a iniciar negociaciones", no se puede inferir la aceptación de una obligación de negociar un acceso soberano al mar.

9 Misma cita. Pár. I03 
En lo relacionado con la reunión de Charaña y su secuencia, la Corte consideró que podría haber surgido dicha obligación si ambas Partes hubiesen expresado la intención de verse obligadas por la Declaración, lo que no hicieron. De todo ello se infiere, dice la Corte, que la Declaración fue un documento político ${ }^{10}$. De la Declaración Conjunta posterior de fecha io de junio de I977, tampoco se puede inferir una obligación. En ella ambos gobiernos acordaron iniciar negociaciones, pero no fueron más allá que de reafirmar la necesidad de proseguir dichas negociaciones, sin mencionar obligación alguna de negociar. La Corte dejó constancia que durante este proceso, la propuesta hecha por Chile a Bolivia, fue consultada por Chile al Perú, de conformidad con lo dispuesto en el art. I del Protocolo Complementario de 1929. Dicha consulta, dice la Corte, fue respondida por Perú, proponiendo situar parte del territorio litoral de Chile bajo la jurisdicción conjunta de los tres Estados, lo que Chile y Bolivia rechazaron. Más adelante, la Corte igualmente desestimó el carácter de Acuerdos Bilaterales dado por Bolivia al llamado "Enfoque Fresco" de $1986-1987^{11}$, a la Declaración de Algarve $^{12}$ y a la Agenda de I3 puntos $^{13}$, por estimar que de ninguna de las situaciones expuestas era posible concluir que

\footnotetext{
10 Misma cita. Pár. 126

11 Misma cita. Pár. I28-I32

12 Misma cita pár. I33 .I35

13 Misma cita. Pár. I36-I39
}

Chile se había obligado a negociar un acceso soberano al Pacífico.

Respecto de las Declaraciones y Hechos Unilaterales, la gran cantidad de declaraciones formuladas por autoridades nacionales a lo largo de nuestra historia, la mayoría de las cuales califica Bolivia como Declaraciones Unilaterales vinculantes, la Corte fijó los criterios para determinar si la declaración de un Estado conlleva obligaciones jurídicas. Dice: Las declaraciones de esta naturaleza pueden ser y con frecuencia lo son, muy precisas. Cuando el Estado autor de la declaración entiende que se está obligando conforme a sus propios términos, esta intención le confiere el carácter de compromiso legal. El Estado, a partir de este momento, debe seguir una línea de conducta consistente con su declaración. Un compromiso de estas naturaleza hecho públicamente y con la intención de obligarse, a pesar de no haberse hecho en el contexto de negociaciones internacionales, es obligatorio". Además, señaló que para determinar los efectos jurídicos de una declaración hecha por una persona representante del Estado, uno debe examinar el contenido real, así como las circunstancias en las que se realizó. Teniendo en cuenta los criterios señalados, la Corte consideró que las declaraciones y otros actos unilaterales de Chile no se expresan en términos de asumir un compromiso jurídico. Respecto de las circunstancias en que se formularon, la Corte no encontró 
evidencia alguna de una intención de Chile de obligarse a negociar ${ }^{14}$.

En cuanto a la Aquiescencia, el Estoppel, las Legítimas Expectativas, y el efecto acumulativo de los fundamentos jurídicos, la Corte no los declaró procedentes, sea por cuanto no existía obligación de responder (Aquiescencia), no reunirse los requisitos requeridos (Estoppel), no tener aplicación en Derecho Internacional (Legítimas expectativas) o que la suma de $0+0+0$ es igual a $\circ$ (efecto acumulativo) ${ }^{15}$.

Bolivia también pretendió fundar su pretensión en las resoluciones emitidas por las Asambleas Generales de la OEA entre 1979 y 1989, resoluciones que "per sé" no son vinculantes y no pueden ser fuente de una obligación internacional, como señaló la Corte, observando, asimismo, que ninguna de ellas indica que Chile esté bajo la obligación de negociar, sino recomiendan que entren en negociaciones.

Un último fundamento se basó en el art. $2 \mathrm{~N}^{\circ} 3$ de la Carta de las Naciones Unidas, disposición que contiene el principio que los Estados deben solucionar sus controversias por medios pacíficos. Este principio, sin embargo, no cita la negociación, y si bien el art. 33 menciona los medios de solución, entre los cuales está la negociación, el principio a aplicar es de la libre elección de ellos. La libre elección de medios, dijo la Corte, se encuentra proclamada, además, en la Resolución 37/10 sobre Arreglo Pacífico de las Controversias Internacionales. Este mismo principio es aplicable a las disposiciones de la Carta de la Organización de Estados Americanos ${ }^{16}$.

\section{Consideraciones finales}

El Presidente de la Corte, el somalí Ahmed Yusuf, terminó la lectura del fallo a mediodía del lunes I de octubre. En base al material presentado, leyó Yusuf, la Corte es incapaz de concluir que Chile tiene la obligación de negociar con Bolivia para alcanzar un acuerdo que otorgue a Bolivia un acceso plenamente soberano al Océano Pacífico y, por consiguiente, no puede aceptar las otras dos peticiones bolivia-

14 Misma cita. Pár. I40-I45

15 Misma cita. Pár. I49-I59; I60-I62, y I72-I64. nas que se basan en la existencia de tal obligación $^{16}$.

Finalizó así un largo proceso de más de cinco años desde que Bolivia presentó su caso a la Corte Internacional de Justicia, sentando a Chile en el banquillo de los demandados. Pero, para hacerlo, debió retirar la reserva que había introducido al firmar el Pacto de Bogotá, la que le permitía demandar por situaciones producidas con anterioridad a la entrada en vigencia del Pacto, cuando se vieran afectados

16 Misma cita. Par. I75. 
sus intereses vitales. Y también debió reconocer el Tratado de 1904, cuya validez puso en duda poco después de su entrada en vigencia y reiteró hasta que recurrió a la presente instancia internacional de justicia.

La sentencia reviste importancia para Chile, pues aclara que de las complicadas relaciones vividas después de la Guerra, ninguna de las negociaciones, conversaciones o declaraciones de nuestras autoridades, obligaron a Chile a negociar.

Aspecto no menor es la comprobación que se trata de un fallo apegado plenamente al Derecho Internacional. La Corte dejó en claro el rol fundamental que juega la negociación en las relaciones bi y multilaterales de los Estados, constituyendo así un instrumento esencial y cotidiano, entre otros, para el arreglo pacífico de sus controversias $^{17}$. El propio juez ad-hoc de Bolivia, Ives Daudet, escribió en su voto disidente que la posición rigurosa adoptada por la Corte se debe a que un Estado no puede verse obligado a negociar si dicho acto no se base en un acto concertado, un acto unilateral o basado en un principio de Derecho Internacional.

La Corte concluyó su tarea con la redacción de un párrafo en que solicita a ambas Partes que no entiendan su decisión como impedimento para continuar su diálogo e intercambios, en un espíritu de buena vecindad, para abordar los asuntos relativos a la situación mediterránea de Bolivia, solución que ambos han reconocido es una materia de interés mutuo. Con voluntad de las Partes, pueden emprenderse negociaciones significativas.

Las últimas palabras del histórico fallo deben ser entendidas en su propio mérito y no como una invocación a regresar al comienzo del largo camino recorrido. Ello sería traicionar los deseos de buena vecindad planteados por el más alto tribunal internacional.

17 Misma cita. Pár. 9I 
